\title{
A Study on Interpersonal Relationships for Social Interactive Television
}

\author{
Niloofar Dezfuli ${ }^{1} \quad$ Mohammadreza Khalilbeigi ${ }^{1}$ \\ ${ }^{1}$ Technical University of Darmstadt \\ 64289 Darmstadt,Germany \\ \{niloo, khalilbeigi, max\}@tk.informatik.tu- \\ darmstadt.de
}

\author{
Max Mühlhäuser ${ }^{1} \quad$ David Geerts ${ }^{2}$ \\ ${ }^{2}$ CUO, IBBT / K.U.Leuven \\ Parkstraat 45, \\ 3000 Leuven, Belgium \\ david.geerts@soc.kleuven.be
}

\begin{abstract}
This paper presents an explorative study investigating the social video watching experience. We particularly investigate the role of interpersonal relationships on social interaction while watching and its link to video genres. The results reveal that the desired relationship for social interactions around video content does not solely depend on strong relationship between viewers. Moreover, program genre plays an important role on social structure preferences for watching television as a shared activity. These results can have considerable impact on designing social interactive television systems to enhance social interactions between remote viewers.
\end{abstract}

\section{Categories and Subject Descriptors}

H.4.3 Information Systems Application: Communications Applications.

\section{General Terms}

Human Factors, Measurement, Design, Experimentation.

\section{Keywords}

Interactive television, Social media, Tie strength, genres.

\section{INTRODUCTION}

As a response to the need for social interaction, researchers have been working on combining television, a popular and already social medium, with social features enabling remote interaction. Most developed social interactive television (iTV) systems support some form of synchronous or asynchronous remote communication between non-collocated viewers with the TV content as a catalyst of topics for conservations. E.g., many social interactive television systems use a buddy list for showing viewers which of their friends are currently (and accidentally) online, in order to stimulate interactivity and sociability amongst them.

These systems however, do not take into account the variation in relationships people have. People have diverse interpersonal relationships as they are participating in various communities, which make them belong to various groups of friends, each of

Permission to make digital or hard copies of all or part of this work for personal or classroom use is granted without fee provided that copies are not made or distributed for profit or commercial advantage and that copies bear this notice and the full citation on the first page. To copy otherwise, or republish, to post on servers or to redistribute to lists, requires prior specific permission and/or a fee.

EuroITV'11, June 29-July 1, 2011, Lisbon, Portugal.

Copyright 2011 ACM 978-1-4503-0602-7/11/06...\$10.00. them with different common interests. Therefore, a buddy list is not a group of equal friends as people's relationships have diverse and complex structures [3]. Research on social iTVs has been more focused on the creation of communication features itself and little has been done to explore people's interpersonal relationships and its effect on social iTV systems. We believe that depending on video content, social television has a greater potential to provide feelings of togetherness if real-life relationships are taken into account.

This paper reports on an explorative study of people's video viewing habits (broadcast or online), targeting both the current and preferred social context of viewing. We study the social context based on a fine-granular classification system of interpersonal relationships. This leads us to derive some patterns which are elaborated more by analyzing the relation with video genres.

\section{RELATED WORK}

There exist a large number of studies which investigate the social structure of people in the context of social media. One of the earliest accounts of the role of different kinds of relationships is found in the work of Granovetter [7]. He introduced the term "tie strength" based on amount of time, emotional intensity, intimacy, and reciprocal services. Gilbert and Karahalios [9] presented a predictive model to map social media data to the tie strength, which can be employed on designing social media elements like privacy controls. Nardi [5] compared friends' and strangers' behaviors while they played collaboratively in World of Warcraft.

The issue of variations in friendships has also been addressed in the domain of social iTV. Luyten et al. [1] created a social TV prototype, called Telebuddies, in which they used Friend of a Friend profiles in order to find common ground between viewers, and thus create subgroups of people with similar interests. Weisz et al. [6] investigated how friends and strangers interact while watching. He found out that friends enjoyed chatting together more significantly than strangers, but strangers felt a little closer with chat than without chat. Geerts and De Grooff [11] presented sociability heuristics for designing social interactive systems. Among others, they recommended that the system should provide awareness about viewing behavior for engaging other viewers. Despite a large body of research on social iTV, we find very little research with a focus on understanding interpersonal relationships. 
Table 1: Classification of Interpersonal Relationships

\begin{tabular}{|c|l|}
\hline Relationship & \multicolumn{1}{c|}{ Description } \\
\hline Close Family & Family members who live together. \\
\hline Far Family & Family members who do not live together. \\
\hline Confidant & $\begin{array}{l}\text { Intimate friends who disclose their personal } \\
\text { information and enjoy each other's company. }\end{array}$ \\
\hline Comforter & $\begin{array}{l}\text { People who help each other not only in a } \\
\text { practical way but also give each other emotional } \\
\text { support. }\end{array}$ \\
\hline Fun & $\begin{array}{l}\text { People who socialize together, but only for fun. } \\
\text { They do not support each other with a deep } \\
\text { level of emotional support. }\end{array}$ \\
\hline Favor & $\begin{array}{l}\text { People who help each other only in a functional } \\
\text { manner. }\end{array}$ \\
\hline Contact & $\begin{array}{l}\text { People who share information related to work } \\
\text { or advancing one's career. }\end{array}$ \\
\hline Associate & $\begin{array}{l}\text { People who do or share a common activity like } \\
\text { a hobby. }\end{array}$ \\
\hline Stranger & People who you do not know at all. \\
\hline
\end{tabular}

\section{METHODOLOGY}

The goal of our study was to investigate the preferred social structure of watching video. More precisely, with this study we want to answer the following research questions:

- What are preferences for social connectedness while remotely watching video material?

- What is the relation between genres and interpersonal relationships?

People have different classifications of their social circle. In order to have consistent data, we created a comprehensible classification of people's relationships including family members, friends, strangers and "nobody", referring to a non-social situation (see table 1). Moreover, we break down the friendship variations into six categories ranging from confidant to associate friends. These are highly inspired by Spencer and Pahl's work as their findings are based on strong empirical material and fully cover a wide spectrum of friendship repertoires [3]. We performed a pilot study in a small scale to ensure that the categories are comprehensible and distinguishable from each other, resulting in a fine-grained yet simplified classification of relationships to help participants categorize their social circle.

We opted for structured diaries as an indirect observation technique, because it allows us to get a deeper insight in people's behavior of watching video over a longer period of time. The diaries were carefully designed to collect as detailed information as possible about watching habits. The participants had to describe in detail which videos they watched each day. We designed the main body of the diary in a way which allowed participants to elaborate more on the videos with respect to different questions. The questions provided us more detail about situations in which the participants watched (either together or alone, with whom on which device) as well as genres of videos. Moreover, we asked participants whether the current situations fulfilled their social needs or not. If not, we asked them to detail their preferred relationships (based on table 1) and briefly describe the reason. We also provided a sample of a completed diary which gave the participants the opportunity to see how they should fill out the diaries.

The study was conducted in Germany and South Korea with an equal number of participants living in household types from families without child (13) to families with one (3) or two children (6). We recruited 22 participants (each country 11 participants) for the study which lasted 14 days. The age of participants ranged from 23 to 50 years, with an average age of 30 $(\mathrm{SD}=6.80)$ and $38(\mathrm{SD}=5.62)$ in Germany and Korea respectively. Nine of the participants were female and thirteen of the participants were male. The participants were selected on the basis that they live in a household and watch live TV or on-demand content at least several times a day. We also ensured that the participants could assign their current relationships with others to all categories according to table 1 . The majority of the participants in both countries had university degree, and in terms of occupational classification, 14 people would be considered as professional or managerial (such as research scientist and engineer), 3 participants are administrative (such as secretary) and 5 were housewives. We thanked all the participants with 10 Euro Amazon gift cards.

\section{RESULTS AND DISCUSSION}

In total, number of video samples elevated to 488 for the whole study (Germany $(\mathrm{G}): 250$, Korea $(\mathrm{K}): 238$ videos). Each participant watched an average of $22(\mathrm{SD}=3.33)$ and $21(\mathrm{SD}=1.49)$ videos in Germany and Korea respectively. Furthermore, each participant also reported having watched 4 to 6 different genres. In terms of device usage, participants watched videos with the same types of devices in both countries: TV (G:64\%, K: 68\% of videos), PC (G:14\%, K:10\% of videos), laptop (G:14\%, K:5\% of videos) and mobile phone (G:8\% , $\mathrm{K}: 17 \%$ of videos). Due to the differences in social and cultural norms across countries, we analyzed the data of each country individually. We performed a qualitative analysis, building up and iteratively refining our coding scheme during the analysis of the diaries. Social and non-social situations were coded separately for relevant behavior. For each country, we first describe the current social context of video watching followed by participants' patterns of their preferences for social connectedness which are elaborated with genres of video content. Finally, we describe nonsocial patterns.

\subsection{Germany}

\subsubsection{Current Patterns of Social Watching}

112 videos recorded in Germany have been collocatedly viewed in social situations ( $44 \%$ of videos). $60 \%$ of the whole videos are watched with strong ties such as close and far family members as well as confidant friends. This can be partially due to the social context of the participants, living alone or in households as 7 participants pointed out the fact that they watch more together only as spend more time together. For the rest of the categories which encompass mainly weak relationships, the number of videos considerably decreased except associate friends. Participants mainly reported in diaries that they assigned their colleagues to this category. "I'm on a business trip with my colleagues, we do everything together here". For 5\% of the videos viewed in Germany, 4 participants also reported that they watched these videos with strangers on their cell phones and laptops. "He [a stranger] asked me about what I was watching and laughing at on my mobile phone". 
Table 2: Preferred Social Structure

\begin{tabular}{|c|c|c|c|c|c|c|c|c|}
\hline \multicolumn{2}{|c|}{ Genre } & News & Film & Soap & Comedy Series & Quiz & Documentary & Sport \\
\hline \multirow{2}{*}{$\begin{array}{c}\text { Relationship } \\
\text { Categories }\end{array}$} & Germany & \multirow{2}{*}{ Family } & Nobody & \multirow{2}{*}{\multicolumn{2}{|c|}{ Fun Friends }} & Ass & triends & \multirow{2}{*}{ All } \\
\hline & South Korea & & Family & & & & Contacts & \\
\hline
\end{tabular}

\subsubsection{Preferences of Social Connectedness}

172 videos documented in Germany (68\% of videos) are preferred to be watched in social situations. In contrast to the current collocated social situations, participants preferred less to watch videos with close and far family members. We found that news is the most frequent genre which German participants would like to watch with their family. They (70\% of news videos, $7 \mathrm{P})$ reported sharing and talking about news as the main reasons for that: "I always inform my wife about weather conditions".

Although people actually watch TV more with their family members but confidant friend $(31 \%$ of the whole videos, all participants) is the most preferred category to watch videos with. A reason might be that confidant friends not only support intimacy and trust like family members but also people in this category involve a high level of enjoyment [3].

Nearly $50 \%$ of the videos are preferred to be watched with weaker relationship categories, particularly comforter, fun and associate friends. Participants reported to highly prefer their fun friends (37\% of soap and comedy videos, 10P) to watch soaps and comedy series. This can be explained due to the fact that this is a category that revolves mainly around having fun [3]. They reported increasing the joy of the watching activity (9P) and repeating funny statements with friends as main reasons for that (6P): "He [the participant's fun friend] made me laugh more " or "We make more jokes out of it" or "We can laugh whenever we repeat the funny expressions together even after month".

In addition, $12 \%$ of the whole videos are preferred to be watched with the associated friend category documented by 9 participants. Interestingly, associate friend is the category that people preferred mostly to watch documentaries with. When looking for an explanation for this, we found some reasons documented in diaries. 7 participants reported that they would like to watch and communicate about the topic of the documentary with whomever they have common interest with. This can explain why people prefer watching these genres with their associated friends. Participants added that in this way they can talk to someone who already knows about this topic (7P) and they may provide additional information (5P): "It was a documentary about dancers and I was excited if I could watch it with two of my friends. We are participating in the same dance class weekly.", "The documentary reported mainly about car racing. I'd like to watch it with associate friends as we professionally play online racing game" or "I'd like to watch it with her(associate friend) because we discussed about the same topic but I could not convince her about what is clearly shown in this program" . By analyzing genres individually, we found that sport genre has a very similar number of videos over almost all types of people's relationships. 5 participants even explicitly wished to watch sports with strangers. They believed that "Sports means: more people, more fun" or "watching football in group is more enjoyable".

To help readers a summary of preferred social connectedness for different genres of each country is given in table 2 .

\subsection{South Korea}

\subsubsection{Current Patterns of Social Watching}

The Korean participants documented that they collocatedly watched videos with others in 114 of videos (47\% of videos). Similar to Germany, family categories have the highest frequencies for social watching in Korea. This fact appeared approximately in $56 \%$ of the samples and was mentioned by all participants.

The Korean participants rarely reported about their social watching experiences with weak relationships. Useful contact is the only category which 5 participants documented that they viewed videos, particularly in a working environment. They reported that "we [colleagues] are together every day, sometimes even on weekends!" or "I cannot watch videos alone in my office, my colleagues are always with me there" as reasons for watching videos with their useful contacts.

\subsubsection{Preferences of Social Connectedness}

The Korean participants preferred watching videos in social situations in 149 of videos ( $62 \%$ of videos). In general, they prefer to watch video with their strong relationship categories such as close and far family members and particularly confidant friends ( $72 \%$ of videos) while watching news (8P) or film (6P). This behavior is similar to the current collocated social watching situations. They reported "I always talk about interesting news with my husband", "The news was related to our daughter education" or "Movies are too long and I would prefer to share my time with my family".

Participants preferred to watch few videos with the rest of the weak relationships. The associated category shows a relative high rank $52 \%$ of quiz videos for 7 participants. In summary, they mentioned enjoy of guessing the answers (5P), presenting their knowledge (7P), and discussing about the topics of questions in quiz $(6 \mathrm{P})$ as main reasons.

In $9 \%$ of the videos, 9 participants documented they would like to watch sports with all types of categories. However, unlike in Germany, we did not code any preferences to watch sport with strangers. "It would be great if I could have all of my friends (confidant, comforter, fun, and associate) present when we won the gold medal" or "Our national favorite player made a goal and it would be more exciting while watching it in group".

\subsection{Patterns of Non-social Situations}

We also analyzed the videos of the category 'nobody' in which the participants wished to watch alone with respect to different genres. This gave us an overview of videos preferred to watch in non-social situations in both countries (G: 78, K: 89 videos). We consider the genres with the highest and lowest frequencies to find out which genres are mostly preferred to be watched in non-social and social situations. The results of our analysis turn out to be very similar across both countries.

We found that news (G: 7P, K: 8P) and films (G: 9P, K: 6P) are the genres which people mainly preferred to watch alone. However, we coded almost the same amount of videos for 
preferences to watch these two genres within families. We can argue that preferring to watch films and news genres in non-social situation is because they need more continuous attention (G: 5P, $\mathrm{K}: 3 \mathrm{P})$ [2]. "It was a complex movie; it was hard to follow if you talk to someone". Other reasons for non-social watching preferences are e.g. mood of participants (G: 10P and K: 6P) and quality of the film or news (G: 3P, K: 3P). These facts can reduce people's willingness to watch these genres together or communicating about them while watching."I'm in bed and it just helps me to sleep."

In contrast, quiz (G: 7P, K: 8P), comedy series (G: 8P, K: 10P), and sports $(\mathrm{G}: 11 \mathrm{P}, \mathrm{K}: 10 \mathrm{P})$ are three genres which participants stated in both countries that they would have more fun in a social situation. This can be explained by the attempt of viewers to predict the outcomes of the quiz while they watch or by the creation of ongoing discussions around comedy series to have more fun together. The participant's desires of watching sports in social situations are not only confirmed by our empirical results but it has also been evidenced by several researchers (see e.g. [4]). Moreover, the results of non-social preferences reflect the findings of [2] in which they investigate the role of program genres in terms of different activities such as talking and sharing.

\section{DESIGN IMPLICATIONS}

Based on the results presented above we can identify some general patterns about the preferences of social connectedness to support remote social watching experience. Our results showed that the nature of some friendships can be matched to certain genre characteristics. Different friendship categories demonstrated remarkably specific behavior related to the social watching experience. For example, associate friends are frequently preferred as co-viewers despite their weak relationships. Since the nature of this category is mainly based on entirely sharing a particular interest or activity, it was highly desired to communicate while watching, especially in quiz and documentary. Hence, social television systems may adapt their buddy list to the content that is being shown. To enhance the potential of communication and the fun of watching in social situations, it is necessary to design the structure of buddy list more effectively so that iTV systems which in some way reflect the desired social structure of viewers instead of group of accidental online friends. As another concrete example, such systems can improve their content recommendations based on the interpersonal relationships between viewers and online friends.

Another odd one out in our relationship preferences is sport which has a fair distribution over all types of interpersonal relationships. We can argue that for sport viewers (in both countries) the quantity of co-viewers is more important rather than the social structure of people. One other interesting issue that implicitly arose in participants' comments was that they would like to follow episodic programs with the same friends whom they watched previous episodes with. This fact can be also used in enhancing social features of social iTV systems such as awareness tools indicating future behavior of viewers.

Although we discussed that social iTV systems should benefit from social structure of watching experience, our results show a relative high desire on watching videos in non-social mode. This suggests that social iTV systems may take factors such as day time, mood, and the context of viewers into account in order to minimize unwanted social interactions.
While most of our findings represent generalized patterns, due to the limited number of participants we were not able to identify possible cross-cultural differences. Moreover, our analysis is limited to what the participants actually documented in their diaries.

\section{CONCLUSION}

This paper contributes the results of an explorative study understanding the role of interpersonal relationships on social video watching habits. We investigate the probable link between the nature of friendship variations and program genres to inform the design of social television systems. We hope that our results can shed light on the role of interpersonal relationships in the context of social iTV systems. While this paper provides a starting point for dealing with more fine-grained relationships in social TV systems, a next step might be to assess how a social TV system can integrate the proposed classification structure and allows to further study how to effectively gather desired friends online around video and television content.

\section{ACKNOWLEDGEMENT}

This work has been supported by the IT R\&D program of MKE/KEIT of South Korea (10035587, Development of Social TV Service Enabler based on Next Generation IPTV Infrastructure).

\section{REFERENCES}

[1] Luyten, K., Thys, K., Huypens, S., and Connix, K. Telebuddies: social stitching with interactive television. Proc. CHIEA'06, 1049-1054.

[2] Geerts, D. , Cesar, P. and Bulterman, D. The Implications of Program Genres for the Design of Social Television Systems. Proc. uxTV'08, 71-80.

[3] Spencer, L. and Pahl, R. Re-Thinking Friendship: Hidden Solidarities Today, New Jersey: Princeton University Press, 2006.

[4] Ducheneaut, N., Moore, R.J., Oehlberg, L., Thorn-ton, J.D., and Nickell, E. Social TV: Designing for distributed, sociable television viewing. International Journal of Human-Computer Interaction, 2008, 136-154.

[5] Nardi, B., and Harris, J. Strangers and friends: Collaborative play in World of Warcraft. Proc. CSCW'06, 149-158.

[6] Weisz, J., Kiesler, S., Zhang, H., Ren, Y., Kraut, R., Konstan, J. Watching together: integrating text chat with video. Proc. CHI'07, 877-886.

[7] Granovetter, M.S. The Strength of Weak ties. The American Journal of Sociology, 1973, 1360-1380.

[8] Boyd, D. Autistic Social Software. The Best Software Writing I. Apress, 35-45.

[9] Gilbert ,E., and Karahalios, K. Predicting tie strength with social media. Proc. CHI'09, 211-220.

[10] Hawkins, R.P., Pingree, S., Hitchon, J., Radler, B., Gorham,B., Kahlor, L., Gilligan, E., Serlin, R.C., Schmidt, T., Kannaovakun, P., and Kolbeins, H. What produces television attention and attention style?. Human Communication Research, 162-187.

[11] Geerts, D. and De Grooff, D. Supporting the Social Uses of Television: Sociability Heuristics for Social TV. Proc. CHI'09, 595-604. 